\title{
Improvement Opportunities for Growers of Ornamental Plants: A Survey of Landscape Architects
}

\author{
M.P. Garber ${ }^{1}$ \\ Department of Horticulture, University of Georgia, P. 0. Box 1209, \\ Tifton, GA 31793-1209

\section{K. Bondari ${ }^{2}$ \\ Department of Statistical and Computer Services, Coastal Plain Experiment Station, Tifton, GA 31793-0748}

Additional index words. plant availability, nursery crops, market research, plant quality

\begin{abstract}
A survey of landscape architects in Georgia was conducted to identify opportunities for nurseries to meet the needs of landscape architects and to improve the quality of installed landscapes. The primary opportunities identified for improvement for growers are to provide regular, frequent plant availability (32\% of respondents); develop new plant varieties for specific needs $(21 \%)$; supply plants that meet specified sizes $(\mathbf{2 0 \%})$; recommend plant varieties for specific conditions $(\mathbf{1 2 \%})$; provide picture of plants $(9 \%)$; and make presentations to landscape architects $(5 \%)$. Additional insight into how growers can help landscape architects achieve a higher quality installed landscape was gained from the question, 'What is the most common complaint you experience regarding plant material installed ?" Landscape architects indicated that plants below specified size $(44 \%)$ and plants below specified quality $(24 \%)$ were the two most common complaints.
\end{abstract}

The landscape industry (growers, landscape contractors, and landscape architects) recognizes that all groups in the landscaping process can benefit from a closer working relationship (Garber, 1991a, 1991b). The

\footnotetext{
Received for publication 9 Dec. 1991. Accepted for publication 15 July 1992. Supported in part by the American Society of Landscape Architects, 4401 Connecticut Ave., NW, Washington, DC 20008; the Southern Nurserymen's Assn., 1511 Johnson Ferry Rd., Suite 115, Marietta, GA 30062; the Horticultural Research Institute, 1250 I St., NW, Suite 500, Washington, DC 20005; and the Tennessee Valley Authority, P.O. Box 1010, Muscle Shoals. AL 35660. We gratefully acknowledge the assistance of Mel Crask, Marketing Dept., and Darrel Morrison, School of Environmental Design, in preparation of the survey. The cost of publishing this paper was defrayed in part by the payment of page charges. Under postal regulations, this paper therefore must be hereby marked advertisement solely to indicate this fact. 'Associate Professor.

${ }^{2}$ Professor.
}

American Society of Landscape Architects (ASLA) is leading the effort to foster closer ties through formation of the "New Alliance" (Benjamin, 1990). Landscape architects play a leading role in the landscaping industry since they determine/influence which plants are used in many of the large commercial, residential, resort, and governmental projects (Garber, 1991c). The project owner generally holds landscape architects responsible for the quality and performance of the installed landscape. In addition, the wholesale value of plant material specified by landscape architects can be substantial compared with the value of plant material produced. In Georgia, the value of plant material specified by landscape architects is $\approx 42 \%$ that of the nursery industry (Garber and Bondari, 1992a). Landscape architects are involved in selection of the production nursery where the landscape contractor obtains plants (Garber and Bondari, 1992b). Nursery producers can benefit from a closer working relationship with this important group that influences demand for plant material. In addition, the entire landscape industry could benefit by improving the quality of the installed landscape.

While discussions to date have focused on the need for more effective interaction among segments of the landscape industry, we found no published information that would give specific guidance to growers on the needs of landscape architects. This study was conducted to provide quantitative data on how growers and landscape architects can a) increase the efficiency of work of each industry segment and b) improve the quality and performance of the installed landscape. The results will also help the landscape industry develop a more formal exchange of information.

The survey instrument was mailed to registered landscape architects in Georgia who are members of ASLA. The members represented 168 landscape architectural firms. The survey contained a cover letter cosigned by M.P.G. and the marketing manager of ASLA highlighting the goals of the survey. The initial mailing was sent in May 1991 and a follow-up mailing to nonrespondents in June 1991. We received completed forms from 62 firms for a $37 \%$ response rate. Data were tabulated and an analysis of the response was conducted using SAS (SAS, 1985).

Landscape architects were asked to a) list up to three ways that the plant producer can help them supply better goods and services, b) indicate the most common complaint they experience regarding plant material installed, and c) rate the quality of plants grown in their state relative to other states (Table $1)$. For open-ended questions ( $a$ and $b$ ), categories of response were developed after a review of all comments. The specific comments were then coded for the appropriate category and frequency of response analyzed by category.

All responses were analyzed by size of firm (Table 2). The firm size is based on the 1990 wholesale value of plant material specified: large ( $\$ 1$ million or more), medium (\$200,000 to $\$ 999,000$ ), and small (less than $\$ 200,000)$. The large firms represented $21 \%$ of the respondent firms and $67 \%$ of the total plant material specified, medium firms represented $37 \%$ of respondent firms and $38 \%$ of the total plant material specified, and small firms represented $42 \%$ of respondents and $6 \%$ of the total plant material specified (Gar- 
Table 1. Survey questions addressed.

1) Please list up to three ways that the plant producer could help you supply better products and services: (a)

(b)

(c)

2) What is the most common complaint you experience regarding plant materials installed?

3) Please rate the quality of plants grown in your state relative to other states:

\begin{tabular}{lccc} 
& Worse & Same & Better \\
Deciduous trees & 1 & 2 & 3 \\
Evergreen trees & 1 & 2 & 3 \\
Broadleaf shrubs & 1 & 2 & 3 \\
Coniferous shrubs & 1 & 2 & 3 \\
Perennials/ground covers & 1 & 2 & 3 \\
Bedding plants & 1 & 2 & 3 \\
Native herbaceous & 1 & 2 & 3 \\
\hline
\end{tabular}

Table 2. Wholesale value of plant material specified by the size of landscape architectural firms.

\begin{tabular}{|c|c|c|c|c|}
\hline \multirow[b]{2}{*}{ Size } & \multirow{2}{*}{$\begin{array}{l}\text { Respondent } \\
\text { firms } \\
\text { (no.) }\end{array}$} & \multicolumn{3}{|c|}{ Plant value specified ${ }^{2}$} \\
\hline & & Mean $^{y}$ & S.E. & Range \\
\hline Large & 12 & $1613 \mathrm{a}$ & 144 & $1000-2500$ \\
\hline Medium & 21 & $379 \mathrm{~b}$ & 45 & $200-800$ \\
\hline Small & 24 & $69 c$ & 9 & $5-150$ \\
\hline
\end{tabular}

${ }^{2}$ Expressed in thousand dollars.

yMean separation within a column at $P<0.01$.

Table 3. Response categories and examples of specific statements of landscape architects to the request, "Please list up to three ways that the plant producer can help you supply better goods and services."

\begin{tabular}{|c|c|}
\hline Category & Statement \\
\hline $\begin{array}{l}\text { 1) Recommend plants for } \\
\text { special conditions }\end{array}$ & $\begin{array}{l}\text { Better livability of plant material during summer months } \\
\text { Suggest plants for wet areas or limited root space } \\
\text { Classify plants on drought tolerance } \\
\text { Do not offer plants that do not grow well in this area }\end{array}$ \\
\hline $\begin{array}{l}\text { 2) Provide pictures/ } \\
\text { drawings of plants }\end{array}$ & $\begin{array}{l}\text { Provide pictures of available plants } \\
\text { Ability to fax sample photos } \\
\text { Videos, photos } \\
\text { Have plants better tagged }\end{array}$ \\
\hline $\begin{array}{l}\text { 3) Provide regular, } \\
\text { frequent plant } \\
\text { availability }\end{array}$ & $\begin{array}{l}\text { Create a constant availability of specified size } \\
\text { Supply yearly (or more often) inventory price lists } \\
\text { Send information on newly introduced species } \\
\text { Tell me he/she doesn't have plants before order arrives without them }\end{array}$ \\
\hline $\begin{array}{l}\text { 4) Develop new items } \\
\text { for specific needs }\end{array}$ & $\begin{array}{l}\text { Develop new and improved varieties to meet trends } \\
\text { More drought-tolerant species } \\
\text { Change attitude toward native plants-start thinking environmentally } \\
\text { Donate new items to arboretums in town }\end{array}$ \\
\hline $\begin{array}{l}\text { 5) Supply plants that } \\
\text { meet specified sizes }\end{array}$ & $\begin{array}{l}\text { Remove inferior plants early on-maintain some level of } \\
\text { in-house standards } \\
\text { Grow a better tree-need a consistent quality } \\
\text { Find a standard way to relate gallon size to plant size } \\
\text { Sell plants by height and spread of foliage-don't list container size only }\end{array}$ \\
\hline $\begin{array}{l}\text { 6) Presentations to } \\
\text { landscape architects }\end{array}$ & $\begin{array}{l}\text { Hold their own plant seminars } \\
\text { Send questionnaires asking about LAs' plant species needs } \\
\text { Visit our office to give presentations - not our clients } \\
\text { Invite LAs to come see what's available }\end{array}$ \\
\hline
\end{tabular}

ber and Bondari, 1992a). The mean value of plant material specified varied significantly with the size of the landscape architectural firm (Table 2).

The six categories of responses to the question "Please list up to three ways that the plant producer can help you supply better goods and services" provide a summary of derstanding of the expectations of landscape architects could facilitate an effective marketing program targeted to this important group. Based on comments in Table 3, landscape architects expect growers to assist in two ways: 1) inform landscape architects about available plants (varieties, quantity, quality, etc.) and 2) provide recommendations on proper use of plants for best performance in the landscape.

The frequency of response by landscape architects (number/percent of firms) for each of the six opportunities for improvement for growers varied by a factor of 6 . The primary opportunity for improvement was to provide regular, frequent plant availability $(24 / 32 \%)$. The next two closely rated opportunities were to develop new items for specific needs (16/ $21 \%$ ) and supply plants that meet specified sizes $(15 / 20 \%)$. Three less recommended opportunities were specifying plants for special conditions $(9 / 12 \%)$, providing pictures or drawings of plants (7/9\%), and giving presentations to landscape architects $(4 / 5 \%)$.

Landscape architects want growers to provide accurate and current listings of available plants (Table 3, Category 3 ). The specific comments suggest that plant growers send the availability listing on a regular basis and include plant sizes and not just container size. Landscape architects expect plant growers to highlight a listing of new varieties. The availability should include a price list that is updated annually or when prices change.

The next highest rated opportunity for growers was to develop new plant varieties to meet specific landscape needs. Several respondents suggested development of more drought-tolerant species. This statement may have been influenced by the recent dry years and the effect of water rationing on landscaping activity. Also suggested was increased availability of native plants to help landscape architects design low-cost landscapes with low water requirements. New varieties should be planted in arboretums and other public gardens so they can be evaluated under landscape conditions. This response is consistent with previous work demonstrating that botanical and public gardens are the most valuable sources of information used by landscape architects to determine which plants to specify (Garber and Bondari, 1992c). Growers might consider working closely with landscape architects to identify future trends and specific landscape requirements before development of new plant varieties.

The third most frequently mentioned opportunity for plant growers was to supply plants that meet specified sizes. Several of the suggestions were directed to growers of containerized plants. Landscape architects prefer that plants in containers be sold by height and width of the foliage and not by container size alone. The sale of plants by container size leads to inconsistent size and quality of plants used in the landscape and has disappointed customers. If plants are sold by container size, landscape architects expect growers to develop industry-wide standards.

Growers should also recommend plants for 
Table 4. Response of landscape architects from different firm sizes to the question, "Please list up to three ways that the plant producer could help you supply better goods and services."

\begin{tabular}{lccr}
\hline & & Firm size ${ }^{2}$ \% response) \\
\cline { 2 - 4 } Improvement opportunity & Small & Medium & Large \\
\hline 1) Rccommcnd plants for special conditions & 4.0 & 27.3 & 5.0 \\
2) Provide pictures/drawings of plants to show & & & 0.0 \\
form and final size & 3.0 & 22.7 & 40.0 \\
3) Provide regular/frequent plant availability & 20.0 & 4.5 & 30.0 \\
4) Develop new items for specific needs & 28.0 & 18.2 & 15.0 \\
5) Supply plants that meet specified sizes & 4.0 & 27.3 & 5.0 \\
6) Presentations to landscape architects & & & \\
\hline
\end{tabular}

${ }^{2}$ Size of firm is based on 1990 wholesale value of plant material specified: large ( $\$ 1$ million or more), medium ( $\$ 200,000$ to $\$ 999,000)$, and small (less than $\$ 200,000$ ).

Table 5. Response categories and examples of specific statements of landscape architects to the question, "What is the most common complaint you experience regarding plant material installed?"

Category
1) Plants below specified
2) Poor installation or
site preparation
site preparation

3) Plants below specified quality

4) Post-plant maintenance

\section{Statement}

Not up to specification size, inconsistent

Plants under or just barely meeting specification size

Certain percentage of installed material not consistent with intent of specs; e.g., tall enough but "light"

Plant material spread and height too small in relation to size of container

Poor health or death of trees installed between May and September

Many low-bid contractors put a $\$ 5.00$ plant in a $5 \mathfrak{e}$ hole

Poor quality preparation of planting soil

Poor bed preparation, drainage problems

They are of poor quality, not full and pruned

Unless we tag in field, plants are of average or low quality Misshapen trees or shrubs

Brings in weeds

Tree guy wires left on trees too long
Over-watering by client

No post-planting maintenance by contractor

Never remove stakes and hoses on trees

Table 6. Response of landscape architects to the question, "What is the most common complaint you experience regarding plant material installed?"

\begin{tabular}{lccc}
\hline & \multicolumn{3}{c}{ Firm size $^{z}$ (\% response) } \\
\cline { 2 - 4 } Complaint category & Small & Medium & Large \\
\hline 1) Plants below specified size & 35.0 & 50.0 & 60.0 \\
2) Poor installation or site preparation & 30.0 & 20.0 & 20.0 \\
3) Plants below specified quality & 25.0 & 30.0 & 10.0 \\
4) Post-plant maintenance & 10.0 & 0.0 & 10.0 \\
\hline
\end{tabular}

${ }^{\mathrm{z} A s}$ described in Table 4.

special landscape and environmental conditions. A list of recommended plants for wet areas, dry conditions, and limited root space was specifically mentioned. This suggests that growers organize plant availability lists based on landscape use and not simply provide alphabetical listing by botanical or common name. Also, the availability list should only include plants that perform well in the geographical area where landscape architects are located or install projects.

Several landscape architects requested photos or other graphical presentations of plants. Specific comments suggested a preference for photos of available plants and not a photo of the premier plant specimen. They need information to make a quality and value judgment on plants to be specified.

Another opportunity for growers was to provide landscape architects with presentations on plants and their cultural requirements. Suggestions include presentations at the offices of landscape architects, grower regular/frequent plant availability information as one of the top three opportunities. This result strongly suggests that nursery operators develop a marketing communications program targeted to landscape architects that includes current availability of plant material.

Additional insight into how growers can work closely with landscape architects to provide better quality installed landscapes is gained from responses by landscape architects when they were asked to list the most common complaint they experience regarding plant material installed in the landscape (Table 5). The complaints were initiated by the client of the landscape architect, i.e., the firm or person that pays for the installed landscape. The four categories of response were a) plants below specified sizes; b) poor installation or site preparation; c) plants below specified quality; and d) post-plant maintenance. The frequency of response for each of the four categories of response was plants below specified size $(24 / 44 \%)$, plants below desired quality $(13 / 24 \%)$, poor installation or site preparation $(12 / 22 \%)$, and postplant maintenance $(5 / 9 \%)$.

An amazing $68 \%$ of the complaints regarding plant material installed were a result of plants below the specified size or quality. These two complaints were the most frequent complaints identified by respondents of all three firm sizes $(60 \%$ for small, $80 \%$ for medium, and $70 \%$ for large; Table 6). These problems can be attributed, all or in part, to the growers who supplied the plants. Landscape architects had identified the supply of plants of specified size as an improvement opportunity for nurseries (Table 3; Category 3). A close review of specific comments on plant size (Table 5, no. 1) suggested that landscape architects view the size specifications to represent the minimum size. Their expectation is that the plants will meet or exceed the specifications; whereas nursery operators may view the specified sizes as a target or maximum size. Complaints experienced by landscape architects also highlight the need for container growers to market plants based on plant size (height and width) and not simply container size.

The comments on plant quality suggest that plants may meet the height requirements but lack the necessary branching or "fullness." This discrepancy applied to trees and shrubs. In some instances, landscape architects believed that, unless they received plants that 
Table 7. Response of landscape architects to the request, "Please rate the quality of plants grown in your state relative to other states."

\begin{tabular}{|c|c|c|c|c|c|c|c|c|c|c|}
\hline \multirow[b]{4}{*}{ Plant category } & \multirow{2}{*}{\multicolumn{6}{|c|}{ Response distribution }} & \multicolumn{4}{|c|}{ Mean score ${ }^{z}$} \\
\hline & & & & & & & \multicolumn{4}{|c|}{ Firm size } \\
\hline & \multicolumn{2}{|c|}{ Worse } & \multicolumn{2}{|c|}{ Same } & \multicolumn{2}{|c|}{ Better } & \multirow[b]{2}{*}{ Small } & \multirow[b]{2}{*}{ Medium } & \multirow[b]{2}{*}{ Large } & \multirow{2}{*}{$\begin{array}{c}\text { All } \\
\text { firms }\end{array}$} \\
\hline & No. & $\%$ & No. & $\%$ & No. & $\%$ & & & & \\
\hline 1) Deciduous trees & 10 & 18 & 36 & 64 & 10 & 18 & $2.0 \mathrm{ab}$ & $2.1 \mathrm{ab}$ & $1.7 \mathrm{~b}$ & $2.0 \mathrm{~b}$ \\
\hline 2) Evergreen trees & 11 & 20 & 37 & 67 & 7 & 13 & $2.0 \mathrm{ab}$ & $1.9 \mathrm{bc}$ & $1.7 \mathrm{~b}$ & $1.9 \mathrm{bc}$ \\
\hline 3) Broadleaf shrubs & 7 & 13 & 35 & 65 & 12 & 22 & $2.1 \mathrm{ab}$ & $2.1 \mathrm{ab}$ & $2.2 \mathrm{ab}$ & $2.1 \mathrm{~b}$ \\
\hline 4) Coniferous shrubs & 11 & 22 & 34 & 70 & 4 & 8 & $1.8 \mathrm{~b}$ & $1.7 \mathrm{c}$ & $2.1 \mathrm{ab}$ & $1.8 \mathrm{c}$ \\
\hline 5) Perennials/ground covers & 4 & 7 & 28 & 49 & 25 & 44 & $2.3 \mathrm{a}$ & $2.4 \mathrm{a}$ & $2.5 \mathrm{a}$ & $2.4 \mathrm{a}$ \\
\hline 6) Bedding plants & 2 & 3 & 29 & 52 & 25 & 45 & $2.3 \mathrm{a}$ & $2.4 \mathrm{a}$ & $2.6 \mathrm{a}$ & $2.4 \mathrm{a}$ \\
\hline 7) Native herbaceous & 7 & 13 & 33 & 61 & 14 & 26 & $2.1 \mathrm{ab}$ & $2.0 \mathrm{~b}$ & $2.4 \mathrm{a}$ & $2.2 \mathrm{~b}$ \\
\hline SE of mean & & & & & & & 0.13 & 0.12 & 0.19 & 0.08 \\
\hline
\end{tabular}

${ }^{2}$ Means within a column bearing different letters differ at $P<0.05$.

'As described in Table 4. Mean score for three firm sizes within each category of plant type did not vary significantly at $P>0.05$.

were selected ("tagged") in the field, they received lower quality material. Quality specifications are often the most difficult to define and, therefore, require extensive communication between landscape architects and growers. If the quality aspects are not clearly stated, growers should take the initiative and request more specifics.

Landscape architects were asked to rate the quality of seven categories of plant material produced in Georgia compared with that produced in other states (Table 7). Plants were rated as worse (1), same (2), or better (3). The mean score for the three firm sizes, within each category of plant type, did not vary significantly. However, the mean score for each size firm and all size firms as a group did vary significantly between the seven categories of plants. Landscape architects of all firms combined rated two categoriesperennials/ground covers and bedding plants-significantly higher than other categories of plants. Four other categories-native herbaceous, broadleaf shrubs, deciduous trees, and evergreen trees-were rated significantly lower. The lowest rating was for coniferous shrubs. The greatest opportunity for improvement in quality by Georgia growers was for coniferous shrubs, evergreen trees, and deciduous trees, since the average score for quality was at or below the quality of other states. Of particular concern to Georgia growers should be that the large firms, which account for $67 \%$ of the wholesale value of plants specified, rated Georgia deciduous and evergreen trees below those of other states. The large firms gave the highest quality ratings to perennials/ground covers, bedding plants, and native herbaceous followed by broadleaf and coniferous shrubs.

The frequency of response by quality rating (worse, same, and better) highlighted which category of plants was below that of other states. The coniferous shrubs, evergreen trees, and deciduous trees received the highest response for "worse" category (Table 7). The frequency of response for the "worse" category equalled or exceeded several of the responses under the "better" category.

The complaints regarding poor installation or site preparation and lack of post-plant maintenance (Table 6) were related to the landscape contractor. However, plant producers should work with landscape contractors to reduce customer complaints, since all segments of the landscape industry are affected by the quality of the installed landscape. For instance, the poor health or death of trees installed between May and September cited in Table 5, Category 2, is an opportunity for growers to work closely with landscape contractors to determine the cause and possible solutions. Special handling or improved cultural techniques employed by growers might improve plant performance during the typically hot, dry summer months.

The complaints received by landscape architects regarding plant material installed were fairly consistent for firms of all sizes (Table 6 ). The most common complaint for respondents from all firms was that plants were below specified size. Complaints regarding plant material below desired quality varied slightly between medium and small firms, with only $10 \%$ of the respondents for large firms expressing concern. This complaint was rated second by medium firms and third by small and large firms.

In summary, the results provide guidance for growers to work more efficiently with landscape architects and to improve the quality of installed landscapes. The time required by landscape architects and growers to identify substitute plants will be reduced when growers supply regular, frequent information on plant availability. Earlier results (Garber and Bondari, 1992b) indicated that landscape architects try to confirm plant availability and that they view growers as a primary source of this information. This study suggests that, in addition to providing landscape architects with nursery catalogs, growers can benefit from supplying a separate listing of available, finished product on a regular basis. Container nurseries should market produce not only by container size but also by size of the plants. This procedure would avoid confusion over plant size and allow growers of larger plants to justify a price differential. In addition, growers could enhance their position with landscape architects and improve the quality of installed landscapes by ensuring that plants they supply meet or exceed the specified size and quality. If the quality or size requirements are not clearly stated in a landscape plan, growers should consult with the landscape architect before sale of plant material. These recommendations could result in a closer working relationship between growers and landscape architects to the economic benefit of both.

The results also suggested an opportunity for university teaching, research, and extension personnel to assist the landscape architecture and nursery professions. Landscape architects play a key role in influencing the use of plant material in the landscape. Yet the survey respondents clearly indicated that they need more information regarding plant performance under various landscape conditions. This response suggested that formal courses and extension short courses in plant materials, plant growth and development, and plant site interaction should receive additional emphasis in the training of landscape architects. University research and extension personnel could work together to periodically survey the landscape industry, identify problems, research solutions, and disseminate the information to both professions. In this role, university personnel assist both professions and help ensure higher quality landscapes for the consumer.

\section{Literature Cited}

Benjamin, P.C. 1990. ASLA and industry leaders hammer out "New Alliance." Nursery News 5(12): 1 .

Garber, M.P. 1991a. Have you hugged your landscape architect today? Georgia Green Industry Nwsl. 2(1):12-18.

Garber, M.P. 1991b. "New Alliance" to survey needs of landscape architects. Nursery News 6(4):20.

Garber, M.P. 1991c. National survey on landscape architects plant needs. Georgia/ASLA Nwsl. 2(3):4.

Garber, M.P. and K. Bondari. 1992a. Landscape architects as related to the landscape/nursery industry: I. Impact on demand for plant material. J. Environ. Hort. 10(2):69-72.

Garber, M.P. and K. Bondari. 1992b. Landscape architects as related to the landscape/nursery industry: II. Selection of the production nursery and plant availability. J. Environ. Hort. 10(2):7377.

Garber, M.P. and K. Bondari. 1992c. Landscape architects as related to the landscape/nursery industry: III. Sources of plant material information. J. Environ. Hort. 10(2):78-80.

SAS Institute. 1985. SAS user's guide: Statistics, version 5 (ed.). SAS Inst., Inc., Cary, N.C. 